\title{
Vacuum assisted birth and risk for cerebral complications in term newborn infants: a population-based cohort study
}

\author{
Cecilia Ekéus $^{{ }^{*}}$, Ulf Högberg ${ }^{2}$ and Mikael Norman ${ }^{3}$
}

\begin{abstract}
Background: Few studies have focused on cerebral complications among newborn infants delivered by vacuum extraction (VE). The aim of this study was to determine the risk for intracranial haemorrhage and/or cerebral dysfunction in newborn infants delivered by VE and to compare this risk with that after cesarean section in labour (CS) and spontaneous vaginal delivery, respectively.

Methods: Data was obtained from Swedish national registers. In a population-based cohort from 1999 to 2010 including all singleton newborn infants delivered at term after onset of labour by VE $(n=87,150)$, CS $(75,216)$ or spontaneous vaginal delivery $(n=851,347)$, we compared the odds for neonatal intracranial haemorrhage, traumatic or non-traumatic, convulsions or encephalopathy. Logistic regressions were used to calculate adjusted (for major risk factors and indication) odds ratios (AOR), using spontaneous vaginal delivery as reference group.

Results: The rates of traumatic and non-traumatic intracranial hemorrhages were 0.8/10,000 and 3.8/1,000. VE deliveries provided $58 \%$ and $31.5 \%$ of the traumatic and non-traumatic cases, giving a ten-fold risk [AOR 10.05 (4.67-21.65)] and double risk [AOR 2.23 (1.57-3.16)], respectively. High birth weight and short mother were associated with the highest risks. Infants delivered by CS had no increased risk for intracranial hemorrhages. The risks for convulsions or encephalopathy were similar among infants delivered by VE and CS, exceeding the OR after non-assisted spontaneous vaginal delivery by two-to-three times.

Conclusion: Vacuum assisted delivery is associated with increased risk for neonatal intracranial hemorrhages. Although causality could not be established in this observational study, it is important to be aware of the increased risk of intracranial hemorrhages in VE deliveries, particularly in short women and large infants. The results warrant further studies in decision making and conduct of assisted vaginal delivery.
\end{abstract}

\section{Background}

Delivery by vacuum extraction (VE) is a common obstetrical procedure in the western world, and in many countries, it has replaced the use of forceps. The use of VE has increased from 6\% in 1980 to $8.8 \%$ in all deliveries in Sweden 2011, while the use of forceps currently is $0.2 \%$ [1] In the US, vacuum-assisted births have declined to $2.8 \%$ of the births in 2011 [2].

While extra-cranial haematomas and skull fractures have been associated with VE assisted deliveries [3-7], a causal link to neonatal intracranial haemorrhage (intracranial

\footnotetext{
* Correspondence: cecilia.ekeus@ki.se

'Department of Women's and Children's Health, Division of Reproductive Health, Karolinska Institutet, Stockholm, Sweden

Full list of author information is available at the end of the article
}

hemorrhages;subarachnoid, subdural, and intracerebral) is less evident [8]. VE is reported to be associated with rare but severe cerebral complications [9], although study limitations have been small sample size and retrospective design $[9,10]$, composite outcomes [11], mixed term and preterm deliveries [12,13], no comparisons of rates of intracranial complications in vacuum extraction and caesarean section (CS) deliveries [9,13]. In addition, few studies have investigated the association between $\mathrm{VE}$ and neonatal encephalopathy and the results are contradictive [13,14].

Intracranial hemorrhage in newborn infants can be observed also without a difficult delivery, and its complexity in etiology was already described a century ago [15]. Modern neuroimaging techniques-such as ultra-

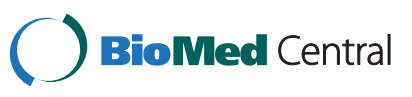


sound, computerized tomography (CT), and magnetic resonance imaging (MRI)-have improved the diagnostic accuracy of neonatal brain damage. MRI in a small clinical series of asymptomatic newborn infants has revealed a high prevalence and high spontaneous resolution of small intracranial hemorrhages in both spontaneous and assisted vaginal births [16-19]. The specific risk for serious intracranial hemorrhages in relation to VE remains however to be clarified.

Sweden with one of the highest rates of VE and lowest rates of CS is well suited for a population-based cohort study comparing the risks for neonatal intracranial hemorrhages and cerebral dysfunction among term newborn infants in relation to mode of delivery. The aim of this study was to determine the risks for intracranial hemorrhages or cerebral dysfunction in newborn infants delivered by VE and to compare these risks with those after cesarean section in labour (CS) and spontaneous vaginal delivery, respectively. Furthermore, a second aim was to determine any selective contribution of mode of delivery apart from other maternal and infant risk factors - to neonatal brain injury.

\section{Methods}

This study was based on information in two national databases held by the Swedish National Board of Health and Welfare, and Statistics Sweden: (A) The Swedish Medical Birth Register includes prospectively collected information on demographic data, reproductive history and complications during pregnancy, delivery and the neonatal period for more than $98 \%$ of all births in Sweden. Using each mother's unique national registration number, it is possible to link information on successive births within the Medical Birth Register and to link information between registries. Maternal characteristics are recorded in a standardized manner during a woman's first visit to antenatal care, which occurs before 15 weeks of gestation in more than $95 \%$ of the pregnancies and (B) The Swedish National Inpatient Register, which covers all public in-patient care. The national registration number, assigned to each Swedish resident at birth, was used for individual record linkage.

The study population was retrieved from the Swedish Medical Birth Register and included all singleton newborn infants in Sweden between 1999 and 2010 delivered at term (gestational age $>37$ weeks +0 days) after the onset of labour by vacuum extraction VE (in all VE $n=87,150$, including failed VE ending in CS $n=3484$ ) by cesarean section in labour CS $(\mathrm{n}=75,216)$, or by spontaneous vaginal delivery $(\mathrm{n}=851,347)$. Stillborn infants, multiple births, infants delivered by elective CS before labour, breech deliveries and forceps-assisted deliveries were excluded. Since the use of forceps has declined from $0.5 \%$ in 1999 to $0.2 \%$ in 2010 and now only constitutes a fraction of all deliveries in Sweden, we decided to exclude this mode of delivery in this study. Thus, the study population included $94 \%$ of all deliveries among term, singleton, live-born infants during the study period.

Information about parity (primi- or multipara), maternal age, height, body mass index (BMI), and mode of delivery was collected from the The Swedish Medical Birth Register. BMI was calculated from measured height and weight, obtained from the first antenatal care visit at 8-10 gestational weeks and categorized into underweight (below $\left.18.5 \mathrm{~kg} / \mathrm{m}^{2}\right)$, normal (18.5-24.9), overweight (25-29.9), obese (>29.9), or missing. CS was defined as abdominal delivery after the onset of labour. Gestational age (GA: categorized into 37-38, 39-41, and 42-45 weeks) was recorded in completed weeks, and was based on routine ultrasound dating performed at 17 to 18 postmenstrual weeks in $97-98 \%$ of all pregnant women. Indications for VE and CS were classified into prolonged labour (O62.0-2, O63.0-9), signs of fetal distress (O68.0-O68.1-9), a combination of these, or none of these using obstetric diagnoses-collected from the Swedish Medical Birth Register or the Swedish National Inpatient Register -classified according to the International Classification of Diseases (ICD) tenth edition (1997 and onwards) revisions.

The following ICD-10 codes were assessed as outcomes: intracranial laceration and haemorrhage due to birth injury (P10), intracranial non-traumatic haemorrhage of foetus and newborn (P52), convulsions of newborn (P90), and other disturbances of the cerebral status of the newborn; encephalopathy (P91). The definition of each outcome is described in detail in Table 1 . Infants that had at least one outcome diagnosis in The Swedish Medical Birth Register or in the Swedish National Inpatient Register were counted as cases. More than $85 \%$ of the outcome diagnoses were retrieved from the Swedish Medical Birth Register and 15\% came from the Swedish National Inpatient Register. The registers do not cover information on when an infant was diagnosed.

During the study period, neonatal diagnoses of an intracranial lesion were based on imaging of the brain using ultrasonography, CT, and/or MRI. During the study period, MRI was introduced and to some extent replaced CT for neonatal brain imaging. The rate of intracranial hemorrages did not change significantly, however, in relation to year of birth. Imaging of the brain was performed on clinical indications in all cases and there was no screening-general or selective, based on risk factors-of asymptomatic infants. A diagnosis of convulsions included infants with clinical signs of convulsions and/or convulsions verified by EEG.

Statistical analysis was performed using proportions and odds ratios (OR) with a 95\% confidence interval (CI) for severe neonatal cerebral complications in relation to mode of delivery, using spontaneous vaginal delivery as 
Table 1 Neonatal outcomes studied in term, singleton newborn infants

\begin{tabular}{|c|c|c|c|}
\hline \multicolumn{4}{|c|}{ Neonatal outcomes } \\
\hline \multirow{2}{*}{$\begin{array}{l}\text { Outcome } \\
\text { Intracranial bleeding }\end{array}$} & \multirow{2}{*}{$\begin{array}{l}\text { Main ICD-code } \\
\text { P10 Intracranial laceration and haemorrhage } \\
\text { due to birth injury }\end{array}$} & \multicolumn{2}{|c|}{ ICD-subgroup } \\
\hline & & 10.0 & Subdural haemorrhage due to birth injury \\
\hline & & 10.1 & Cerebral haemorrhage due to birth injury \\
\hline & & 10.2 & Intraventricular haemorrhage due to birth injury \\
\hline & & 10.3 & Subarachnoid haemorrhage due to birth injury \\
\hline & & 10.4 & Tentorial tear due to birth injury \\
\hline & & 10.8 & $\begin{array}{l}\text { Other intracranial lacerations and haemorrhages due to } \\
\text { birth injury }\end{array}$ \\
\hline & & 10.9 & $\begin{array}{l}\text { Unspecified intracranial laceration and haemorrhage due } \\
\text { to birth injury }\end{array}$ \\
\hline & $\begin{array}{l}\text { P52 Intracranial non-traumatic haemorrhage } \\
\text { of foetus and newborn }\end{array}$ & 52.0 & $\begin{array}{l}\text { Intraventricular (non-traumatic) haemorrhage, grade 1, } \\
\text { Subependymal haemorrhage (without intraventricular extension) }\end{array}$ \\
\hline & & 52.1 & $\begin{array}{l}\text { Intraventricular (non-traumatic) haemorrhage, grade } 2 \text {, } \\
\text { Subependymal haemorrhage with intraventricular extension }\end{array}$ \\
\hline & & 52.2 & Intraventricular (non-traumatic) haemorrhage, grade 3, \\
\hline & & & $\begin{array}{l}\text { Subependymal haemorrhage with both intraventricular and } \\
\text { intracerebral extension }\end{array}$ \\
\hline & & 52.3 & $\begin{array}{l}\text { Unspecified intraventricular (non-traumatic) haemorrhage of foetus } \\
\text { and newborn }\end{array}$ \\
\hline & & 52.4 & Intracerebral (non-traumatic) haemorrhage of fetus and newborn \\
\hline & & 52.5 & Subarachnoid (non-traumatic) haemorrhage of foetus and newborn \\
\hline & & 52.6 & $\begin{array}{l}\text { Cerebella (non-traumatic) and posterior fossa haemorrhage } \\
\text { of fetus and newborn }\end{array}$ \\
\hline & & 52.8 & $\begin{array}{l}\text { Other intracranial (non-traumatic) haemorrhages of foetus } \\
\text { and newborn }\end{array}$ \\
\hline & & 52.9 & $\begin{array}{l}\text { Intracranial (non-traumatic) haemorrhage of foetus and } \\
\text { newborn, unspecified }\end{array}$ \\
\hline
\end{tabular}

\section{Neonatal cerebral P 90 Convulsions of newborn} dysfunction

P91 Other disturbances of cerebral status of newborn/Encephalopathy

\author{
P91.0 Neonatal cerebral ischemia \\ P91.1 Acquired periventricular cysts of newborn \\ P91.2 Neonatal cerebral leukomalacia \\ P91.3 Neonatal cerebral irritability \\ P91.4 Neonatal cerebral depression \\ P91.5 Neonatal coma \\ P91.6 Hypoxic ischemic encephalopathy of newborn \\ P91.8 Other specified disturbances of cerebral status of newborn \\ P91.9 Disturbance of cerebral status of newborn, unspecified
}

the reference group (SPSS 20.0 for Windows software package). Three models were used to assess the relationship between the different modes of delivery and the risk for neonatal cerebral complications, one crude and two adjusted (Models 1 and 2). The included co-variates have been shown previously to be related to instrumental deliveries and were related to the outcomes in cross tabulations [20-22]. In Model 1, we adjusted for the following confounders or co-variates: year of birth; parity; maternal age, height, and BMI; and infant birthweight and GA. In Model 2 , we added shoulder dystocia and the indication for operative delivery. The year of birth was entered as a continuous variable in accordance with a linear secular trend, and all other variables were entered as categories. In the adjusted model, we refrained from stratifying by hospital type or by annual number of deliveries due to the fact that outcomes were overall rare and each strata would have contained only very limited or no numbers. Missing 
data were entered as a separate category in the analyses. The study was approved by the Regional Ethical Review Board in Stockholm, Dnr 2008/1322-31.

\section{Results}

During the study period, the proportion of women delivered by VE was on average of $8.6 \%$ with an annual variation from 7.6 to $9.1 \%$, and by CS (in labour), 7.4\%, with an annual variation from $6.6 \%$ to $7.9 \%$. The rate of VE varied between $6.2 \%$ to $13.4 \%$ between hospitals, and the rate of CS varied from $6.1 \%$ to $11.0 \%$. The numbers of newborn infants with any cerebral complication delivered by VE was $906(104 / 10,000)$ and by CS the numbers were 652 $(87 / 10,000)$ compared with $1,227(14 / 10,000)$ after spontaneous vaginal delivery.

The rate of newborn infants with intracranial hemorrhages was 4.9/10,000 in university hospitals and 3.8/ 10,000 in county hospitals. The corresponding rates for encephalopaties/convulsions were 23.9 and 25.0, respectively. The differences between university and county hospitals were not statistically significant.

Maternal and perinatal characteristics by mode of delivery

Primiparas were overrepresented among women delivered by VE and CS, while multiparas were overrepresented among women delivering vaginally without operative assistance. In the CS group, more infants were post-term (GA 42-45 weeks), and more women were overweight or obese as compared to women in the VE and vaginal delivery groups; see Table 2.

Neonatal intracranial haemorrhage by mode of delivery

In all, 86 newborn infants were diagnosed with intracranial laceration and haemorrhage classified as traumatic intracranial hemorrhages), corresponding to a rate of 0.8 / 10,000 births, and 384 infants were diagnosed with nontraumatic intracranial hemorrhages), corresponding to a rate of 3.8/10,000 births. Eight infants had both diagnoses. Among the infants diagnosed with traumatic intracranial hemorrhages, $58 \%$ were delivered by VE, $7.1 \%$ with CS and $35 \%$ by spontaneous vaginal delivery. Among those diagnosed with non-traumatic intracranial hemorrhages, the corresponding proportions were $32 \%, 13 \%$, and $56 \%$, respectively, for each mode of delivery.

The rate of neonatal intracranial hemorrhages (both traumatic and non-traumatic intracranial hemorrhages) was more than six times greater among newborns delivered by VE (19.0 per 10,000) and more than doubled among those born by CS (7.3 per 10,000) compared with infants born by spontaneous vaginal delivery ( 2.8 per $10,000)$. Intracranial hemorrhages were generally more frequent among infants of primiparas than of multiparas women. Among VE-delivered infants, the rate of intracranial hemorrhages increased gradually with increasing
Table 2 Maternal and perinatal characteristics by mode of delivery in a population-based cohort of singleton pregnancies starting with labour and ending at term

\begin{tabular}{rrrr}
\hline $\begin{array}{r}\text { Spontaneous } \\
\text { vaginal }\end{array}$ & Emergency CS & $\begin{array}{r}\text { Vacuum } \\
\text { extraction }\end{array}$ \\
$\mathbf{N = 1 , 0 1 0 , 2 2 9}$ & $\mathbf{N = 8 5 1 , 3 4 7}$ & $\mathbf{N}=\mathbf{7 5 , 2 1 6}$ & $\mathbf{N = 8 7 , 1 5 0}$ \\
\hline$\%$ & $\%$ & $\%$
\end{tabular}

Maternal age (years)

$-19$

1.9

20-24

13.6

1.1

1.6

25-29

31.2

10.1

13.5

30-34

35-39

$>39$

34.6

15.6

2.8

Missing

0.3

28.1

32.8

Maternal height $(\mathrm{cm})$

$-155$

156-160

12.8

161-165

166-170

$>170$

Missing

36.1

34.8

19.4

14.4

2.6

0.3

Maternal BMI

Underweight

Normal

Overweight

Obese

Missing$$
0.4
$$

Parity

Multipara

$\begin{array}{rr}8.1 & 4.7 \\ 19.4 & 15.2 \\ 27.1 & 26.1 \\ 23.9 & 26.9 \\ 15.0 & 20.9 \\ 6.4 & 6.1\end{array}$

Primipara

Indication

Signs of fetal distress

Prolonged labour

Both

None of these

Gestational week

37-38

39-41

42-45

41.2

Infant birthweight (g)

$\leq 3000$

4001-4500 
Table 3 Frequencies and crude rates of neonatal intracranial haemorrhage (diagnoses P10 and P52) in term singleton infants categorized by mode of delivery

\begin{tabular}{|c|c|c|c|c|c|c|c|c|c|}
\hline \multirow[t]{4}{*}{$N=1,010,229$} & \multicolumn{9}{|c|}{ Traumatic and non-traumatic intracranial haemorrhage of fetus and newborn $n=462$} \\
\hline & \multirow{2}{*}{\multicolumn{3}{|c|}{$\begin{array}{l}\text { Vaginal delivery } \\
\mathrm{N}=851,347\end{array}$}} & \multirow{2}{*}{\multicolumn{3}{|c|}{$\begin{array}{l}\text { Emergency cesarean section } \\
\qquad N=75,216\end{array}$}} & \multirow{2}{*}{\multicolumn{3}{|c|}{$\begin{array}{l}\text { Vacuum extraction } \\
\qquad N=87,150\end{array}$}} \\
\hline & & & & & & & & & \\
\hline & $\mathbf{N}$ & $\mathrm{n}$ & $1 / 10000$ & $\mathrm{~N}$ & n & $1 / 10000$ & $\mathbf{N}$ & $\mathrm{n}$ & $1 / 10000$ \\
\hline Total & 851,347 & 241 & 2.8 & 75,216 & 55 & 7.3 & 87,150 & 166 & 19.0 \\
\hline \multicolumn{10}{|l|}{ Maternal age (years) } \\
\hline-19 & 16,256 & 4 & 2.5 & 859 & 0 & & 1,384 & 1 & 7.2 \\
\hline 20-34 & 676,207 & 177 & 2.6 & 55,934 & 44 & 7.9 & 70,645 & 137 & 19.4 \\
\hline$<34$ & 156,454 & 59 & 3.8 & 18,151 & 11 & 6.1 & 14,820 & 28 & 18.9 \\
\hline Missing & 2,430 & 1 & 4.1 & 272 & 0 & & 301 & 0 & \\
\hline \multicolumn{10}{|l|}{ Maternal height (cm) } \\
\hline-155 & 30,767 & 14 & 4.6 & 6,116 & 7 & 11.4 & 4,074 & 18 & 44.2 \\
\hline $156-160$ & 108,658 & 28 & 2.6 & 14,622 & 12 & 8.2 & 13,278 & 31 & 23.3 \\
\hline 161-165 & 210,094 & 68 & 3.2 & 20,403 & 10 & 4.9 & 22,733 & 38 & 16.7 \\
\hline $166-170$ & 242,617 & 67 & 2.8 & 17,965 & 11 & 6.1 & 23,470 & 39 & 16.6 \\
\hline$>170$ & 208,213 & 53 & 2.5 & 11,276 & 8 & 7.1 & 18,240 & 24 & 13.2 \\
\hline Missing & 50,998 & 11 & 2.2 & 4,834 & 7 & 14.5 & 5,355 & 16 & 29.9 \\
\hline \multicolumn{10}{|l|}{ Maternal BMI } \\
\hline Underweight & 12,843 & 4 & 3.1 & 643 & 0 & & 1,372 & 1 & 7.3 \\
\hline Normal & 311,523 & 68 & 2.2 & 22,768 & 11 & 4.8 & 33,207 & 62 & 18.7 \\
\hline Overweight & 121,733 & 42 & 3.5 & 13,246 & 10 & 7.5 & 12,395 & 24 & 19.4 \\
\hline Obese & 49,278 & 22 & 4.5 & 7543 & 9 & 11.9 & 4,369 & 8 & 18.3 \\
\hline Missing & 355,970 & 105 & 2.9 & 31,016 & 25 & 8.1 & 35,807 & 71 & 19.8 \\
\hline \multicolumn{10}{|l|}{ Parity } \\
\hline Multipara & 516,619 & 101 & 2.0 & 26,521 & 16 & 6.0 & 18,091 & 26 & 14.4 \\
\hline Primipara & 334,728 & 140 & 4.2 & 48,695 & 39 & 8.0 & 69,059 & 140 & 20.3 \\
\hline \multicolumn{10}{|l|}{ Indication } \\
\hline Signs of fetal distress & 9,403 & 10 & 10.6 & 22,320 & 38 & 17.0 & 22,320 & 57 & 18.8 \\
\hline Prolonged labour & 54,204 & 28 & 5.2 & 24,738 & 8 & 3.2 & 24,738 & 64 & 19.2 \\
\hline Both & 1,834 & 2 & 10.9 & 6,225 & 2 & 3.2 & 6,225 & 22 & 23.4 \\
\hline None of these & 785,906 & 201 & 2.6 & 21,933 & 7 & 3.2 & 21,933 & 23 & 16.4 \\
\hline \multicolumn{10}{|l|}{ Gestational week } \\
\hline $37-38$ & 138,934 & 66 & 4.8 & 12,641 & 14 & 11.1 & 9,949 & 24 & 24.1 \\
\hline $39-41$ & 656,094 & 154 & 2.3 & 48,343 & 32 & 6.6 & 66,020 & 111 & 16.8 \\
\hline $42-45$ & 56,319 & 21 & 3.7 & 14,232 & 9 & 6.3 & 11,181 & 31 & 27.7 \\
\hline \multicolumn{10}{|l|}{ Infant birthweight (g) } \\
\hline$\leq 3000$ & 60,674 & 44 & 5.5 & 8,334 & 14 & 16.8 & 7,985 & 13 & 16.3 \\
\hline $3001-3500$ & 280,255 & 69 & 2.5 & 19,163 & 9 & 4.7 & 26,914 & 38 & 14.1 \\
\hline $3501-4000$ & 320,650 & 69 & 2.2 & 24,807 & 18 & 7.3 & 32,870 & 63 & 19.2 \\
\hline $4001-4500$ & 136,803 & 42 & 3.1 & 16,236 & 7 & 4.3 & 15,596 & 35 & 22.4 \\
\hline$>4500$ & 30,861 & 17 & 5.5 & 6,455 & 2 & 3.1 & 3,571 & 14 & 39.2 \\
\hline Missing & 2,104 & 0 & & 221 & 5 & 226.2 & 214 & 3 & 140.2 \\
\hline
\end{tabular}




\begin{tabular}{|c|c|c|c|c|c|c|c|c|c|}
\hline \multicolumn{10}{|c|}{ Shoulder dystocia } \\
\hline No & 849,910 & 240 & 2.8 & 75,212 & 55 & 7.3 & 86,310 & 155 & 18.0 \\
\hline Yes & 1,437 & 1 & 7.0 & 4 & 0 & & 840 & 11 & 131.0 \\
\hline
\end{tabular}

birthweight (except infants with a birthweight below 3000 gram), increasing maternal BMI, and decreasing maternal height. Infants diagnosed with shoulder dystocia had the highest rates, 131/10,000, Table 3 .

\section{Neonatal convulsions and encephalopathy by mode of delivery}

In all, 1,763 newborn infants were diagnosed with convulsions and 1,629 with encephalopathy), 583 infants had both these diagnoses.

Infants delivered by CS or VE had six-to-seven times higher rates of convulsions or encephalopathy than those born by spontaneous vaginal delivery. The rate increased with increasing maternal BMI in all types of delivery, and with decreasing maternal height, particularly in the VE-group. In the VE-group, increasing infant birthweight was gradually related to neonatal convulsions or encephalopathy, whereas in the CS-group this relationship was inversely related. Finally, the rate of convulsions or encephalopathy was almost doubled in VE-delivered infants born after 41 weeks of GA as compared to those born in weeks 39-41; see Table 4 .

Table 5 shows crude and adjusted odds ratios for the neonatal outcomes by mode of delivery, with infants born by spontaneous vaginal delivery as the reference group. Here we present intracranial hemorrhages as two separate outcomes: intra-cranial lacerations and haemorrhage due to birth injury and, intracranial non-traumatic haemorrhage of foetus and newborn. After adjustment for indication for operative delivery and other co-variates, newborn infants delivered by VE had a ten-fold higher risk for traumatic intracranial hemorrhages and more than a doubled risk for non-traumatic intracranial hemorrhages, whereas infants delivered by CS had no increased risk for either traumatic or non-traumatic intracranial hemorrhages. Maternal characteristics, parity, GA, and birthweight (Model 1) explained 25\%, and indication for instrumental delivery (Model 2), a further $21 \%$ of the observed risk increase for traumatic intracranial hemorrhages in infants delivered by VE compared to spontaneous vaginal delivery. The corresponding proportions for non-traumatic intracranial hemorrhages were 30\% and $61 \%$, respectively.

After adjustment for indication for operative delivery and other co-variates, newborn infants delivered by VE or CS faced more than a doubled risk for convulsions or encephalopathy as compared with infants delivered vaginally without operative assistance.

\section{Discussion}

In this national cohort study, we found traumatic intracranial hemorrhages in $6 / 10,000$ and of non-traumatic intracranial hemorrhages in 14/10,000 newborn infants delivered at term by VE. The ORs for intracranial hemorrhages after VE were significantly higher (ten-fold higher for traumatic and doubled for non-traumatic haemorrhage) compared with ORs found after delivery by CS and non-assisted vaginally delivery. High birthweight and a short mother were associated with the highest ORs for neonatal intracranial hemorrhages after VE. The rates of neonatal convulsions or encephalopathy were two to three times higher, but almost the same in both VE deliveries and CS. This indicates that different mechanisms are involved in the development of the two types of cerebral complications.

Our study confirms the previously described association between VE-assisted birth and increased risk for neonatal intracranial hemorrhages, and provides robust data on incidence and risk factors for this complication. The finding that VE but not CS was associated with increased risk for neonatal intracranial hemorrhages contrasts, however, to previous observations. There is only one large population-based and nowadays old (from 1992-94) study in which a relation between all types of operative delivery (VE, forceps and CS) and increased rates of neonatal intracranial hemorrhages was found. Based on these findings, the authors concluded that abnormal labour, rather than mode of delivery contributed to increased risk for intracranial injury [23].

In the present study we investigated infants admitted for neonatal care because of clinical symptoms after birth. A neonatal diagnosis of intracranial haemorrhage, convulsion, or cerebral dysfunction most likely represents the most severe degrees of these complications [24].

In VE deliveries, we found particularly high rates in of all cerebral complications among infants with high birthweight. This finding is consistent with another study [10] and indicates that extractions may become more difficult with increasing birthweight. In addition, short maternal stature and high maternal BMI were gradually associated with intracranial hemorrhages. All these factors are associated with prolonged labour and 
Table 4 Frequencies and crude rates of convulsions and other disturbances of cerebral function (ICD10 diagnoses P90 and P91) in term singleton infants categorized by mode of delivery

\begin{tabular}{|c|c|c|c|c|c|c|c|c|c|}
\hline \multirow[t]{4}{*}{$N=1,010,229$} & \multicolumn{9}{|c|}{ Convulsions or encephalopathy $n=2,587$} \\
\hline & \multirow{2}{*}{\multicolumn{3}{|c|}{$\begin{array}{l}\text { Vaginal delivery } \\
\qquad N=851,347\end{array}$}} & \multirow{2}{*}{\multicolumn{3}{|c|}{$\begin{array}{l}\text { Emergency cesarean section } \\
\qquad N=75,216\end{array}$}} & \multirow{2}{*}{\multicolumn{3}{|c|}{$\begin{array}{l}\text { Vacuum extraction } \\
\qquad \mathrm{N}=87,150\end{array}$}} \\
\hline & & & & & & & & & \\
\hline & $\mathbf{N}$ & $\mathrm{n}$ & $1 / 10,000$ & $\mathrm{~N}$ & $\mathrm{n}$ & $1 / 10000$ & $\mathrm{~N}$ & n & $1 / 10000$ \\
\hline Total & 851,347 & 1,113 & 13.1 & 75,216 & 627 & 83.4 & 87,150 & 847 & 97.2 \\
\hline \multicolumn{10}{|l|}{ Maternal age (years) } \\
\hline-19 & 16,256 & 16 & 9.8 & 859 & 6 & 69.8 & 1,384 & 11 & 79.5 \\
\hline 20-34 & 676,207 & 875 & 12.9 & 55,934 & 457 & 81.7 & 70,645 & 673 & 95.3 \\
\hline$>34$ & 156,454 & 217 & 13.9 & 18,151 & 160 & 88.1 & 14,820 & 161 & 108.6 \\
\hline Missing & 2,430 & 5 & 20.6 & 272 & 4 & 147.1 & 301 & 2 & 66.4 \\
\hline \multicolumn{10}{|l|}{ Maternal height (cm) } \\
\hline-155 & 30,767 & 52 & 16.9 & 6,116 & 46 & 75.2 & 4,074 & 65 & 159.5 \\
\hline $156-160$ & 108,658 & 167 & 15.4 & 14,622 & 120 & 82.1 & 13,278 & 174 & 131.0 \\
\hline 161-165 & 210,094 & 313 & 14.9 & 20,403 & 143 & 70.1 & 22,733 & 233 & 102.5 \\
\hline $166-170$ & 242,617 & 281 & 11.6 & 17,965 & 155 & 86.3 & 23,470 & 194 & 82.7 \\
\hline$>170$ & 208,213 & 224 & 10.8 & 11,276 & 107 & 94.9 & 18,240 & 131 & 71.8 \\
\hline Missing & 50,998 & 76 & 14.9 & 4,834 & 56 & 115.8 & 5,355 & 50 & 93.4 \\
\hline \multicolumn{10}{|l|}{ Maternal BMI } \\
\hline Underweight & 12,843 & 9 & 7.0 & 643 & 3 & 46.7 & 1,372 & 6 & 43.7 \\
\hline Normal & 311,523 & 343 & 11.0 & 22,768 & 165 & 72.5 & 33,207 & 288 & 8.67 \\
\hline Overweight & 121,733 & 170 & 14.0 & 13,246 & 109 & 82.3 & 12,395 & 141 & 113.8 \\
\hline Obese & 49,278 & 105 & 21.3 & 7,543 & 77 & 102.1 & 4,369 & 59 & 135.0 \\
\hline Missing & 355,970 & 486 & 13.7 & 31,016 & 273 & 88.0 & 35,807 & 353 & 98.6 \\
\hline \multicolumn{10}{|l|}{ Parity } \\
\hline Multipara & 516,619 & 514 & 9.9 & 26,521 & 265 & 99.9 & 18,091 & 177 & 97.8 \\
\hline Primi & 334,728 & 599 & 17.9 & 48,695 & 362 & 74.3 & 69,059 & 670 & 97.0 \\
\hline \multicolumn{10}{|l|}{ Indication } \\
\hline Signs of fetal distress & 9,403 & 81 & 86.1 & 22,320 & 415 & 185.9 & 22,320 & 300 & 102.6 \\
\hline Prolonged labour & 54,204 & 140 & 25.8 & 24,738 & 49 & 19.8 & 24,738 & 158 & 83.5 \\
\hline Both & 1,834 & 16 & 87.2 & 6,225 & 42 & 67.5 & 6,225 & 80 & 160.4 \\
\hline None of these & 785,906 & 876 & 11.1 & 21,933 & 121 & 55.2 & 21,933 & 309 & 60.9 \\
\hline \multicolumn{10}{|l|}{ Gestational week } \\
\hline $37-38$ & 138,934 & 178 & 12.8 & 12,641 & 94 & 74.4 & 9,949 & 103 & 103.5 \\
\hline $39-41$ & 656,094 & 807 & 12.3 & 48,343 & 419 & 86.7 & 66,020 & 581 & 88.0 \\
\hline $42-45$ & 56,319 & 128 & 22.7 & 14,232 & 114 & 80.1 & 11,181 & 163 & 145.8 \\
\hline \multicolumn{10}{|c|}{ Infant birth weight (g) } \\
\hline$\leq 3000$ & 80,674 & 149 & 18.5 & 8,334 & 111 & 133.2 & 7,985 & 59 & 73.9 \\
\hline $3001-3500$ & 280,255 & 298 & 10.6 & 19,163 & 166 & 86.6 & 26,914 & 230 & 85.5 \\
\hline $3501-4000$ & 320,650 & 344 & 10.7 & 24,807 & 184 & 74.2 & 32,870 & 298 & 90.7 \\
\hline $4001-4500$ & 136,803 & 205 & 15.0 & 16,236 & 102 & 62.8 & 15,596 & 167 & 107.1 \\
\hline$>4500$ & 30,861 & 87 & 28.2 & 6,455 & 29 & 44.9 & 3,571 & 61 & 170.8 \\
\hline Missing & 2,104 & 30 & 142.6 & 221 & 35 & $1,583.7$ & 214 & 32 & 1495.3 \\
\hline
\end{tabular}


Table 4 Frequencies and crude rates of convulsions and other disturbances of cerebral function (ICD10 diagnoses P90 and P91) in term singleton infants categorized by mode of delivery (Continued)

\begin{tabular}{|c|c|c|c|c|c|c|c|c|c|}
\hline \multicolumn{10}{|c|}{ Shoulder dystocia } \\
\hline No & 849,910 & 1,064 & 12.5 & 75,212 & 627 & 83.4 & 86,310 & 775 & 89.8 \\
\hline Yes & 1,437 & 49 & 341.0 & 4 & 0 & & 840 & 72 & 857.1 \\
\hline
\end{tabular}

instrumental delivery [21] and might be due to a relative cephalopelvic disproportion.

Although VE was related to significantly increased rates of intracranial hemorrhages, it is not clear whether the extraction as such could cause cerebral complications or whether it is the complications that lead to the need for a VE delivery that causes intracranial hemorrhages. The axial pressure gradient to the head in labour peaks during the second stage of delivery, and few cesarean deliveries are done during second stage of labour. Thus dystocic labour that results in a delivery by vacuum or cesarean may have the same diagnosis, but certainly the infant born by vacuum-assisted delivery should have been exposed to a higher pressure (duration and force) due to labour per se.

A major strength of this study was the nationwide population-based design, allowing for accurate estimates of rare adverse events, such as severe neonatal cerebral complications of clinical relevance. We were able to include data on risk factors, potential confounders, and outcomes collected independently from one another and without involving the study subjects, thus minimizing various types of bias (e.g., selection, recall). Another advantage was the inclusion of the main indications for VE and CS, enabling us to address the question of confounding by indication. The main exposures-proportion of deliveries by VE and CS, showed homogeneity over time but varied among types of hospital. The main outcome, intracranial hemorrhages, did not differ in relation to year of birth, in either university or county hospitals.

Limitations are that we could not verify the registrystated indication for operative delivery, and we did not have information on the severity and timing of complications indicating operative delivery. Moreover, the registry does not provide specific information about the type of VE instrument used, level, position, and attitude of the fetal head in the pelvis when applying VE, location of placement of the vacuum cup, traction work, skill of the obstetrician, pressure, exposure time and cup detachments. In addition, the register does not provide information about use of oxytocin and application of fundal pressure both increasing the axial pressure on the presenting part. Malmström, who developed the modern ventouse, showed in an experiment that applied external pressure is spread over a sphere while the pressure within the sphere increased by $6 \%$ [25], in contrast to external

Table 5 Logistic regression (odds ratios: OR, crude and adjusted) for intracranial laceration and haemorrhage due to birth injury (P10), intracranial non-traumatic haemorrhage (P52), neonatal convulsions (P90) or other disturbances of cerebral status of newborn (P91) by mode of delivery

\begin{tabular}{|c|c|c|c|c|c|c|}
\hline \multirow[b]{2}{*}{ Mode of delivery } & \multicolumn{6}{|c|}{ P 10 intracranial laceration and haemorrhage due to birth injury } \\
\hline & $\mathbf{N}$ & $\mathbf{n}$ & $1 / 10000$ & Crude OR 95\% Cl & Model 1 & Model 2 \\
\hline Vaginal & 851,347 & 30 & 0.4 & 1.0 & 1.0 & 1.0 \\
\hline CS & 75,216 & 6 & 0.8 & $2.26(0.94-5.44)$ & $1.43(0.58-3.53)$ & $1.27(0.46-3.50)$ \\
\hline VE & 87,150 & 50 & 5.7 & $16.29(10.36-25.62)$ & $12.43(7.58-20.38)$ & $10.05(4.67-21.65)$ \\
\hline \multirow[t]{2}{*}{ Total } & $1,013,713$ & 86 & 0.8 & & & \\
\hline & \multicolumn{6}{|c|}{ P 52 intracranial non-traumatic haemorrhage } \\
\hline Vaginal & 851,347 & 214 & 2.5 & 1.0 & 1.0 & 1.0 \\
\hline CS & 75,216 & 49 & 6.5 & $2.59(1.90-3.54)$ & $1.69(1.22-2.35)$ & $1.03(0.70-1.53)$ \\
\hline VE & 87,150 & 121 & 13.9 & $5.53(4.42-6.91)$ & $4.18(3.29-5.30)$ & $2.23(1.57-3.16)$ \\
\hline \multirow[t]{2}{*}{ Total } & $1,013,713$ & 384 & 3.8 & & & \\
\hline & \multicolumn{6}{|c|}{ P 90 and/or P91 convulsions and/or encephalopathy } \\
\hline Vaginal & 851,347 & 1,113 & 13.1 & 1.0 & 1.0 & 1.0 \\
\hline CS & 75,216 & 627 & 83.4 & $6.42(5.82-7.08)$ & $5.02(4.52-5.58)$ & $2.49(2.17-2.87)$ \\
\hline VE & 87,150 & 847 & 97.2 & $7.50(6.85-8.20)$ & $6.55(5.95-7.21)$ & $2.61(2.27-3.00)$ \\
\hline Total & $1,013,713$ & 2,587 & 25.5 & & & \\
\hline
\end{tabular}

Model 1 ORs adjusted for year of birth, maternal age, maternal height and BMI, parity, gestational age and infant birthweight.

Model 2 ORs also adjusted for shoulder dystocia indications of operative delivery (signs of foetal distress, prolonged labor or foetal distress and prolonged labor). 
fundal pressure increasing the pressure gradient by $17 \%$ [26]. It might be the case that failed VE could represent worst cases of child outcome, but exclusion of those cases did not significantly change the results. Bias due the high number of missing height and BMI is not probable, neither it is a systematic missing in the the Swedish Medical Birth Register nor it is a lack of power in the study sample.

Infant diagnosis as outcome measures also might have limitations such as lack of uniform guidelines on indication for neuroimaging and diagnostic evaluation of newborn infants with clinical suspicion of central nervous dysfunction, as well as changes in neuroimaging diagnostics over time. However, the rates of intracranial hemorrhages did not differ in relation to year of birth or between university and county hospitals.

As diagnostic procedures where done on clinical indications, detection bias with underestimation of the rate of intracranial hemorrhages in the spontaneous vaginal delivered could not excluded [16-19]. However, underestimation of the true intracranial hemorrhages -rate following VE may also have occurred. In a case series of term infants $(\mathrm{n}=913)$ screened with transfontanellar ultrasound after $\mathrm{VE}$, the rate of intracranial homorrhages was reported to be 4.6 times higher $(0.87 \%)$ than in our study [9]. In that study, most of the patients were reported to exhibit "reassuring clinical status" and only one infant with intracranial hemorrhages was admitted for neonatal intensive care.

\section{Conclusions}

Newborn term infants delivered by VE at term have in general low but significantly higher rates of intracranial haemorrhages compared with those born by CS or by a non-assisted vaginal delivery, also after taking indications of operative delivery into account. High infant birthweight and short maternal height were associated with the highest risk for cerebral complications after VE. A cautious interpretation of these results could be awareness of the increased risk of intracranial haemorrhage in vacuumassisted deliveries, particularly in short women expecting a large infant. However, causality has not been established and more studies are needed to disentangle whether the risks observed herein can with certainty be attributed to detection bias, inherent instrumentation, technique problems or residual confounding.

\footnotetext{
Abbreviations

AOR: Adjusted odds ratios; BMI: Body mass index; Cl: Confidence interval; CS: Cesarean section; CT: Computerized tomography; GA: Gestational age; MRI: Magnetic resonance imaging; OR: Odds ratios; VE: Vacuum extraction.
}

\section{Competing interests}

There are no conflicts of interest for any of the authors. There are no financial competing interests.

\section{Authors' contributions}

CE had the idea for the study, designed it, carried out the statistical analysis, and wrote the first draft of the manuscript. UH and MN contributed to the interpretation of results and writing of the manuscript and approved the final version of the submitted article. All authors read and approved the final manuscript.

\section{Disclosure of funding}

Supported by grants from the Swedish Research Council.

\section{Author details}

'Department of Women's and Children's Health, Division of Reproductive Health, Karolinska Institutet, Stockholm, Sweden. 'Department of Women's and Children's Health, Uppsala University, Uppsala, Sweden. ${ }^{3}$ Department of Clinical Science, Intervention and Technology, Division of Pediatrics, Karolinska Institutet, Stockholm, Sweden.

Received: 27 August 2013 Accepted: 13 January 2014

Published: 20 January 2014

\section{References}

1. Socialstyrelsen: Swedish National Board of Health and Welfare: Statistics on Swedish Births. Available at: http://www.socialstyrelsen.se/publikationer2013/ 2013-12-16.

2. Martin JA, Hamilton BE, Ventura SJ, Osterman MJ, Mathews TJ: Births: final data for 2011. Natl Vital Stat Rep 2013, 62:14.

3. Doumouchtsis SK, Arulkumaran S: Head trauma after instrumental births. Clin Perinatol 2008, 35:69-83.

4. Doumouchtsis SK, Arulkumaran S: Head injuries after instrumental vaginal deliveries. Curr Opin Obstet Gynecol 2006, 18:129-134.

5. Uchil D, Arulkumaran S: Neonatal subgaleal hemorrhage and its relationship to delivery by vacuum extraction. Obstet Gynecol Surv 2003, 58:687-693.

6. Swanson AE, Veldman A, Wallace EM, Malhotra A: Subgaleal hemorrhage: risk factors and outcomes. Acta Obstet Gynecol Scand 2012, 912:260-263.

7. O'Mahony F, Hofmeyr GJ, Menon V: Choice of instruments for assisted vaginal delivery. Cochrane Database Syst Rev 2010, 10(11):CD005455.

8. King SJ, Boothroyd AE: Cranial trauma following birth in term infants. Br J Radiol 1998, 71:233-238.

9. Simonson C, Barlow P, Dehennin N, Sphel M, Toppet V, Muriollo V, et al: Neonatal complications of vacuum-assisted delivery. Obstet Gynecol 2007, 109:626-633.

10. Pollina J, Dias MS, Li V, Kachurek D, Arbesman M: Cranial birth injuries in term newborn infants. Pediatr Neurosurg 2001, 35:113-119.

11. Baskett TF, Allen VM, O'Connell CM, Allen AC: Fetal trauma in term pregnancy. Am J Obstet Gynecol 2007, 197:499. e1-7.

12. Werner EF, Janevic TM, Illuzzi J, Funai EF, Savitz DA, Lipkind HS: Mode of delivery in nulliparous women and neonatal intracranial injury. Obstet Gynecol 2011, 118:1239-1246.

13. Demissie K, Rhoads GG, Smulian JC, Balasubramanian BA, Gandhi K, Joseph $\mathrm{KS}$, et al: Operative vaginal delivery and neonatal and infant adverse outcomes: population based retrospective analysis. BMJ 2004, 329:24-29.

14. Walsh C, Robson M, McAuliffe FM: Mode of delivery and adverse neonatal outcomes. Obstet Gynecol 2013, 121:122-128.

15. Warwick M: Cerebral hemorrhage of the newborn. Am J Med Sci 1919, CLVIII:95-104

16. Whitby EH, Griffiths PD, Rutter S, Smith MF, Sprigg A, Ohadike P, et al: Frequency and natural history of subdural haemorrhages in babies and relation to obstetric factors. Lancet 2004, 13(363):846-851.

17. Looney CB, Smith JK, Merck LH, Wolfe HM, Chescheir NC, Hamer RM, et al: Intracranial hemorrhage in asymptomatic neonates: prevalence on MR images and relationship to obstetric and neonatal risk factors. Radiology 2007, 242:535-541.

18. Rooks VJ, Eaton JP, Ruess L, Petermann GW, Keck-Wherley J, Pedersen RC: Prevalence and evolution of intracranial hemorrhage in asymptomatic term infants. Am J Neuroradio/ 2008, 29:1082-1089.

19. Squier W, Mack J: The neuropathology of infant subdural haemorrhage. Forensic Sci Int 2009, 30(187):6-13.

20. Elvander C, Högberg U, Ekéus C: The influence of fetal head circumference on labour outcome: a population-based register study. Acta Obstet Gynecol Scand 2012, 91:470-475. 
21. Sandstrom A, Cnattingius S, Wikstrom AK, Stephansson O: Labour dystocia- risk of recurrence and instrumental delivery in following labour-a population- based cohort study. BJOG 2012, 119:1648-1656.

22. Elvander C, Ekéus C, Gemzell-Danielsson K, Cnattingius S: Reason for the increasing use of vacuum extraction in Sweden: a population-based study. Acta Obstet Gynecol Scand: in press July 2013

23. Towner D, Castro MA, Eby-Wilkens E, Gilbert WM: Effect of mode of delivery in nulliparous women on neonatal intracranial injury. N Engl J Med 1999, 341:1709-1714.

24. Brouwer AJ, Groenendaal F, Koopman C, Nievelstein RJ, Han SK, de Vries LS: Intracranial hemorrhage in full-term newborns: a hospital-based cohort study. Neuroradiology 2010, 52:567-576.

25. Malmström T: The vacuum extractor, an obstetrical instrument and the parturiemeter, A tokographic device (PhD Thesis). Karolinska Institutet. Acta Obstet Gynaecol 1957, 36(3):5-50.

26. Buhimschi CS, Buhimschi IA, Malinow AM, Kopelman JN, Weiner CP:

The effect of fundal pressure manoeuvre on intrauterine pressure in the second stage of labour. BJOG 2002, 109:520-526.

doi:10.1186/1471-2393-14-36

Cite this article as: Ekéus et al:: Vacuum assisted birth and risk for

cerebral complications in term newborn infants: a population-based cohort study. BMC Pregnancy and Childbirth 2014 14:36.

\section{Submit your next manuscript to BioMed Central and take full advantage of:}

- Convenient online submission

- Thorough peer review

- No space constraints or color figure charges

- Immediate publication on acceptance

- Inclusion in PubMed, CAS, Scopus and Google Scholar

- Research which is freely available for redistribution 